\title{
Using Decision Lattice Analysis to Model IOT-based Companies' profit
}

\author{
Nazanin Talebolfakhr \\ Faculty of Industrial Engineering, K. N. Toosi University of Technology, Tehran, Iran \\ n_fakhr@email.kntu.ac.ir \\ Seyed Babak Ebrahimi* \\ Faculty of Industrial Engineering, K. N. Toosi University of Technology, Tehran, Iran \\ b_ebrahimi@kntu.ac.ir \\ Donya Rahmani \\ Faculty of Industrial Engineering, K. N. Toosi University of Technology, Tehran, Iran \\ drahmani@kntu.ac.ir
}

Received: 24/Aug/2020 Revised: 12/Dec/2020 Accepted: 02/Jan/2021

\begin{abstract}
Demand uncertainty and high initial investments for IOT-based projects lead to analyzing various types of options, especially real options in project execution to decrease these uncertainties. In this study, we investigate the firms' expected profits that resulted from appropriate chosen static and dynamic pricing strategies namely low-pricing, high-pricing, and contingent pricing combined with binomial decision lattices. Besides, the reciprocal influence between pricing strategies and IOT investment could provide useful insights for the firms that confront demand uncertainties in selling the firms' products. We propose a model which is the integration of binomial decision lattices, which have been calculated by Real Option Super Lattice Solver 2017 software, and pricing policies under uncertainty. The results provide insights into what pricing strategies to choose based on the project's real option value and the level of the firm uncertainty about the purchasing of the high-value consumer. Among the mentioned static and dynamic pricing strategies, high-pricing and contingent pricing strategies under different situations can be selected and expected profits of each of the strategies will be calculated and compared with each other. On the contrary, as the low-pricing strategy resulted in the lowest option value, it will not be scrutinized in this study. Experimental results show that if the IOT investment level and high-value consumer purchasing likelihood are high, the firm will implement the high-pricing strategy, otherwise choosing the contingent pricing due to the demand uncertainty would be appropriate.
\end{abstract}

Key words: IOT; Pricing Strategies; Demand Uncertainty; Binomial Decision Lattice; Real Options

\section{1- Introduction}

The Internet Of Things (IOT) implementation has been increased in previous years. Various kinds of companies and organizations are using IOT as an essential part of their business because of creating value, bringing new opportunities to the firm, and realizing customer behaviors [1].

IOT has been implemented in pervasive areas such as customer relationship management (CRM), transportation, healthcare, logistics, manufacturing, personal life, home appliances, financial and banking sector, and risk management $[1,2,3,4,5]$. As monitoring and forecasting customers' behaviors and customer satisfaction have become an issue in a competitive market [6, 7], IOT systems play an essential role in choosing pricing decisions and demand planning that leads to reducing demand uncertainty.
Making an appropriate decision is extremely necessary for project life. Binomial decision lattice analysis is an approach that is capable of implementing uncertainties in any period of the project and decides to continue or abandon that project and they could be applied in plenty of situations such as evaluating real and financial option prices $[8,9,10]$. Because of the complexity of applying real option in projects [11], it has rarely been used in technology-based projects, namely IT and IOT product projects. Moreover, obtaining higher expected profits of selling these products is a matter that the IOT-based companies have confronted; hence, how to obtain higher expected profits in different situations according to the IOT level investment, is the question that will be responded in this study. Based on what has been explained, the main contribution of this paper is to propose a model that how IOT-based firms could achieve an expected profit for the company according to the chosen pricing decisions. 
The remainder of this article is organized as follows. Section 2 reviews internet of things, pricing strategies, and real option analysis. Section 3 proposes the model of this contribution. Section 4 provides the decision lattices and expected profits of chosen pricing strategies. Section 5 concludes what had been explained and provides suggestions for further research.

\section{2- Literature Review}

Our research is intently based on three streams of literature: internet of things definitions and visions, pricing strategies under uncertainty, and real option valuation that is combined with binomial decision lattices.

\section{2-1- Internet of Things (IOT)}

Internet of things as a new phenomenon that is also wellknown as the Web of Things (WOT), is still in incipient stages where everybody is attempting to explain this technology according to their visions and such as other emerging technologies, it has complex social and economic implications $[2,12,13,14,15,16]$. The IOT importance in industries and even our personal lives could not be denied. The number of connected objects and global IOT market size have been increasing, so far; therefore, investing in IOT and inspecting the impact of IOT investment on various companies' selling pricing schemes for technology-based products and services due to high demand uncertainty to earn higher profits for companies, have become an issue in recent years.

\section{2-2- Pricing Under Uncertainty}

Demand uncertainty typically happens when the firms' sellers are not able to predict consumer behavior and demand for the different types of their products and services; hence, applying innovative dynamic pricing strategies that reflect customer behaviors and preferences are necessary for most of the firms regarding their business $[1,17,18,19,20,21,22,23,24,25]$. For instance, the sellers could improve the firms' profits by implementing contingent pricing that is well-suited in e-commerce and IT services and products [26]. On the other hand, static pricing strategies namely low-price strategy and high-price strategy also play a noticeable role in the business process in which both of these types of strategies can be influenced by IOT investment [1].

\section{2-3- Real Option Analysis}

Project uncertainties that impact future cash flows can be managed by management flexibility tools such as various types of real options, play an important role in these uncertain situations due to the ability to enhance the expected returns or reduce its expected losses [11]. These options can be implemented to expand, wait, contract, or abandon the project during its execution and evaluated by different methods $[8,27,28]$.

IT and IOT projects as emerging technologies in recent years are not common projects because of requiring high initial investments and confronting high uncertainties and risks during the execution time [29]; hence in this paper, we contribute to a model that decreases these uncertainties by implementing real options combined with decision lattices in the production process and IOT investment in selling strategies.

Therefore, this model lead to decide effectively on doing the project and following that, selling the products which were produced during that project.

\section{3- Model Setup}

Traditional valuation methods namely discounted cash flow method (DCF) and dividend valuation models because of not applying managerial flexibility, have brought some constraints for the investors. The existence of some managerial flexible tools in the projects are necessary because the investors are an aspirant for making decisions during the project life; hence, in this paper, we are going to focus on and analyze implementing real options in projects by creating a discrete binomial lattice and proposing expected profits for IOT-based companies according to their chosen pricing strategy.

\section{3-1- Real Option Valuation}

The Black and Sholes and Prasad Kodukula innovative models have been implemented to value both financial and real options [27, 28]. Among various techniques which were proposed by Kodukula, binomial lattice analysis is our chosen method to value real options in technologybased projects. This valuation will be implemented in three steps as follows:

\section{3-1-1- Present Value}

The project present value at time 0 is determined by the discounted cash flow (DCF) method. Three scenarios are going to be considered with the DCF method which leads to three present values at time 0 , namely optimistic, average, and pessimistic. The present value of the project is measured as follows:

$P V=\frac{F V}{(1+r)^{n}}$ 
Where PV is the present value, FV is the future value, $r$ is a discount rate per period, and $\mathrm{n}$ is the number of periods. Optimistic and pessimistic present values respectively $P V_{o p t}$ and $P V_{\text {pes }}$ can also be calculated similar to Eq. (1), and it is clear that $P V_{a v g}$ is the average of optimistic and pessimistic present values in each of the periods.

\section{3-1-2- Volatility Assumption}

The management assumption approach which is based on three mentioned scenarios and appropriate in technology-based projects will be applied to estimate project volatility as follows [28]:

$\sigma=\frac{\ln \left(\frac{P V_{o p t}}{P V_{p e s}}\right)}{4 \sqrt{T}}$

\section{3-1-3- Binomial Lattice Analysis}

Binomial lattice method in comparison with the BlackSholes model and Monte Carlo simulation provides more flexibility in the project because of the transparent concepts which can be easily explained to the upper managers.

The present value, risk-neutral probabilities, and up and down movement factors are the rudimentary factors to create a binomial lattice that are calculated as follows:

$u=\exp (\sigma \sqrt{\delta t})$

$d=\exp (-\sigma \sqrt{\delta t})$

In Eq. (4), T was the option life, where $\delta t$ is the number of lattice steps during the project execution.

The risk-neutral probability can be measured by:

$p=\frac{\exp (r \delta t)-d}{u-d}$

Where $r$ is a risk-free interest rate and other factors have been determined, so far.

After calculating option parameters and creating the binomial lattice, the option values at each node can be calculated by a backward approach while asset valuation is determined forward.

\section{3-2- IOT-based Firms' Profits}

Among the dynamic and static pricing strategies defined before, contingent pricing (CP), low-price strategy (LP) and high-price strategy (HP) will be the chosen pricing strategies and their expected profits will be derived in this research. In this study, low-value and high-value consumers are called LV and HV respectively.
Assume a firm has one unit of product to sell the consumers and in each period, one type of consumer will show up; the LV consumer who has full certainty will show up in the first determined period, while the HV consumer will come up with less certainty.

Investing in IOT at the level of $\rho \in(0,1)$, leads to increasing the purchasing likelihood of an $\mathrm{HV}$ consumer which is measured as follows:

$\tilde{q}(\rho)=\left(q-q_{0}\right) \rho+q_{0}$

Where $\mathrm{q}$ is the maximum likelihood that an HV consumer will purchase the product and $q_{0}$ is the $\mathrm{HV}$ consumer purchasing likelihood without considering IOT investment. The capital cost which is the convex function of $\rho$ is calculated as follows:

$$
c(\rho)=-\frac{1}{2} c \rho^{2}
$$

Where $\mathrm{c}$ is a capital cost coefficient in IOT investment.

Under LP, the firm exclusively targets LV consumers and HV consumers will be ignored completely. The firm's profit in this policy is [1]:

$\pi_{L}=-\frac{1}{2} c \rho^{2}+p_{L}$

IOT implementation can be a factor that increases the value of the product or service in the consumer's opinion, so IOT can influence a consumer's product valuation significantly which can be measured by the following equation [1]:

$v_{i}=v_{i 0}(1+a \rho), a \geq 0, i=H, L$

Where a is the benefit capture coefficient and $v_{i 0}$ is the product value to HV and LV consumers when IOT has not been invested

Under HP, the firm only emphasizes on HV consumers and misses the chance of selling to an LV consumer; however if the $\mathrm{HV}$ consumer does not show up, the firm will receive a salvage price $\left(p_{S}\right)$. Hence, The firm's expected profit is [1]:

$\pi_{H}=-\frac{1}{2} c \rho^{2}+\left(q-q_{0}\right)\left(p_{H}-p_{S}\right) \rho+q_{0}\left(p_{H}-p_{S}\right)+$

$p_{S}$

Under CP, Since the consumers do not arrive with each other at the same time, the firm can sell the product to an LV consumer but reserves a right to reassign the product to an HV consumer in the second period. The firm's expected profit in this situation is [1]: 
$\pi_{C P}=-\frac{1}{2} c \rho^{2}+\left(\left(q-q_{0}\right) \rho+q_{0}\right)\left(p_{H}-v_{L 0}(1+\right.$

$a \rho+p L$

\section{3-3- IOT-based Firms' Pricing Strategies Combined with Binomial Lattices}

Assume a technology-based project such as IOT device production, which has been valued by decision lattice analysis, and for decreasing the uncertainties during the project execution, we implemented real options. Dynamic and static pricing strategies will be chosen as selling policies in the firm; thus, the strategy which is resulted in a higher real option value will be selected. J. Zhang et al. (2008) proposed a decision lattice with different stages which was modeled with high-end and low-end service customers [30]. However, in this paper, our approach is summarized in three lattices which include high pricing, low pricing, and contingent pricing which are related to high-value and low-value consumers who are willing to purchase technology-based products, not services.

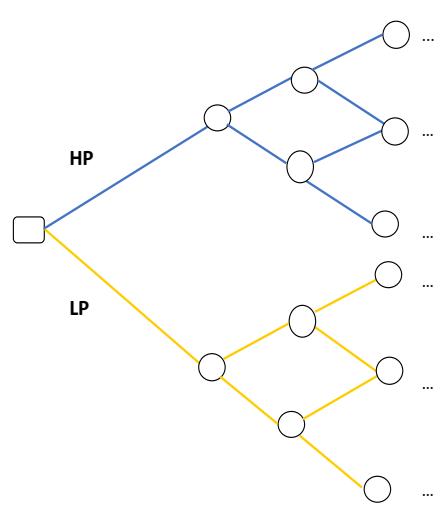

Fig. 1 HP and LP Approach

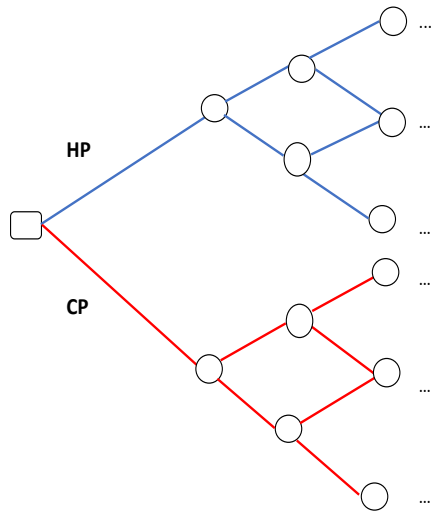

Fig. 2 HP and CP Approach

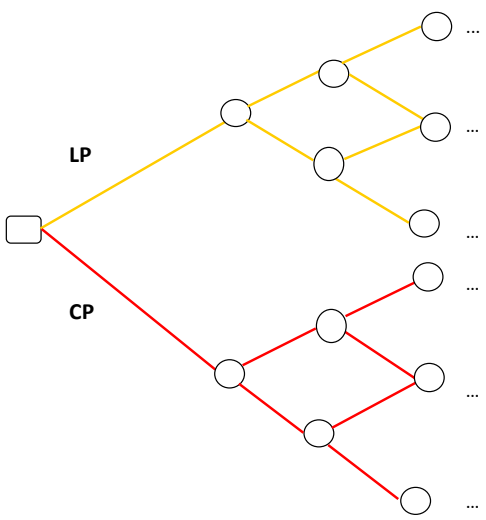

Fig. 3 LP and CP Approach

\section{4- Model Analysis}

We will illustrate our approach with a technologybased four-period project such as IOT device production, which is calculated by binomial decision lattices.
Project future cash flows have been predicted by applying three scenarios namely, optimistic, average, and pessimistic scenarios that are related to high pricing, contingent pricing, and low pricing strategies respectively. The spreadsheet is shown in Table 1.

Table 1: Project spreadsheet

\begin{tabular}{|c|c|c|c|c|c|c|c|c|c|c|}
\hline \multirow[t]{2}{*}{ Period } & \multirow[t]{2}{*}{ Year } & \multicolumn{3}{|c|}{ Investments and Costs } & \multicolumn{3}{|c|}{ Revenue } & \multicolumn{3}{|c|}{ Cash Flows } \\
\hline & & Pessimistic & Average & Optimistic & Pessimistic & Average & Optimistic & Pessimistic & Average & Optimistic \\
\hline 0 & 2020 & 27,454 & 27,454 & 27,454 & - & - & - & -27454 & -27454 & -27454 \\
\hline 1 & 2021 & 32,945 & 28,899 & 24,853 & 75,080 & 105,44 & 135,728 & 42,135 & 76,505 & 110,875 \\
\hline 2 & 2022 & 36,139 & 31,789 & 27,439 & 89,116 & 125,345 & 161,574 & 52,978 & 93,556 & 134,135 \\
\hline 3 & 2023 & 47,206 & 39,736 & 32,266 & 112,133 & 156,681 & 201,230 & 64,927 & 116,945 & 168,964 \\
\hline 4 & 2024 & 70,809 & 52,451 & 34,093 & 132,396 & 203,686 & 274,976 & 61,586 & 151,234 & 240,882 \\
\hline
\end{tabular}

The appropriate discount rate is the risk-free rate which is considered $1.25 \%$. Discounting cash flows to time 0 will result in $P V_{\text {pes }}=\$ 186,991, \quad P V_{a v g}=\$ 395,937$,

$P V_{\text {opt }}=\$ 604,884$, and the project annual volatility is $15 \%$. 


\section{4-1- Project Valuations' Binomial Lattices According to Pricing Strategies}

In this subsection, a real option which results in threefold expansion of current operations at a cost of $\$ 900,000$ will be applied in the project. Pricing strategies' approaches are as follows:

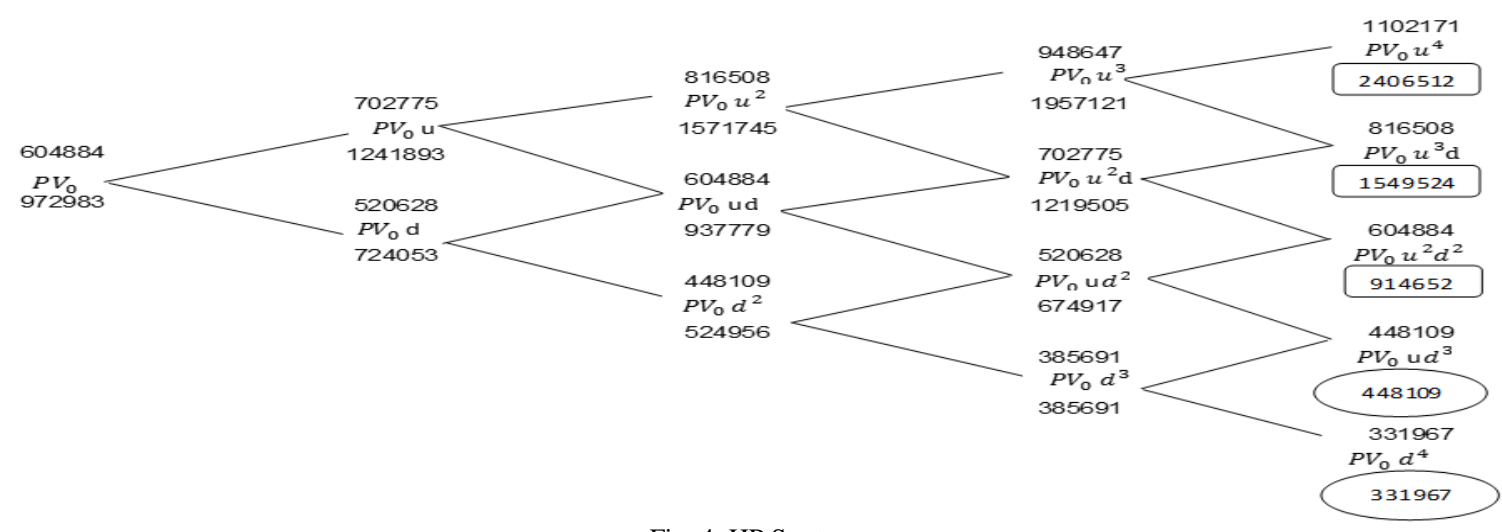

Fig. 4 HP Strategy

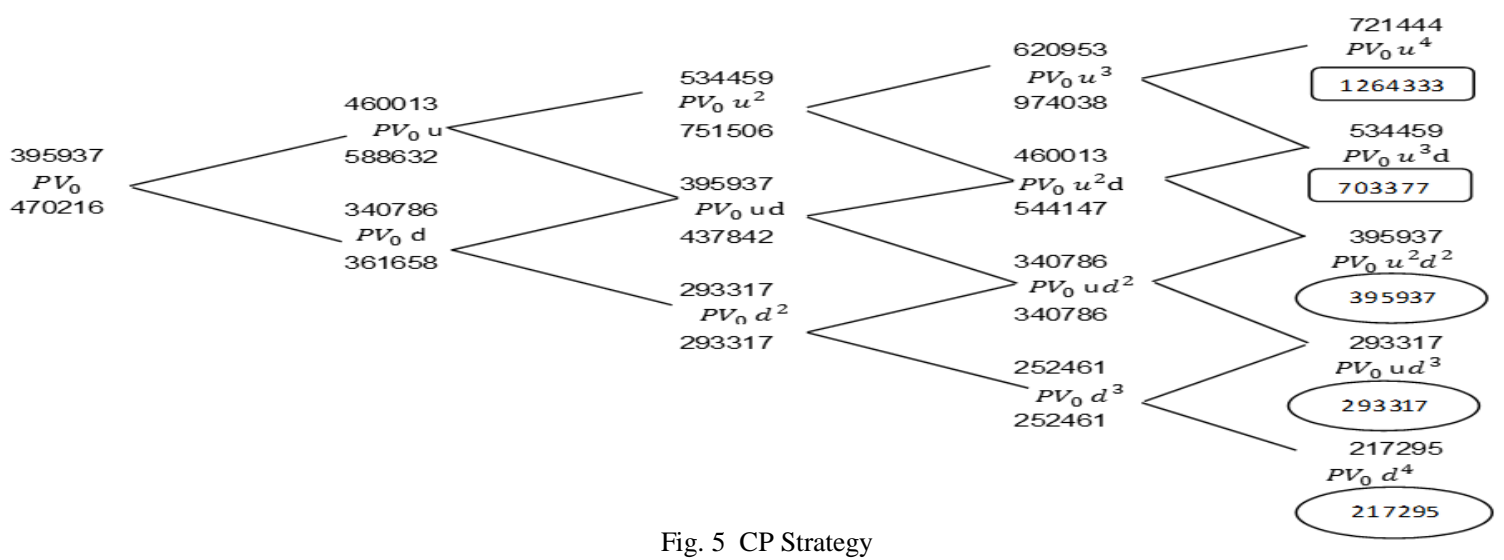

Fig. 5 CP Strategy

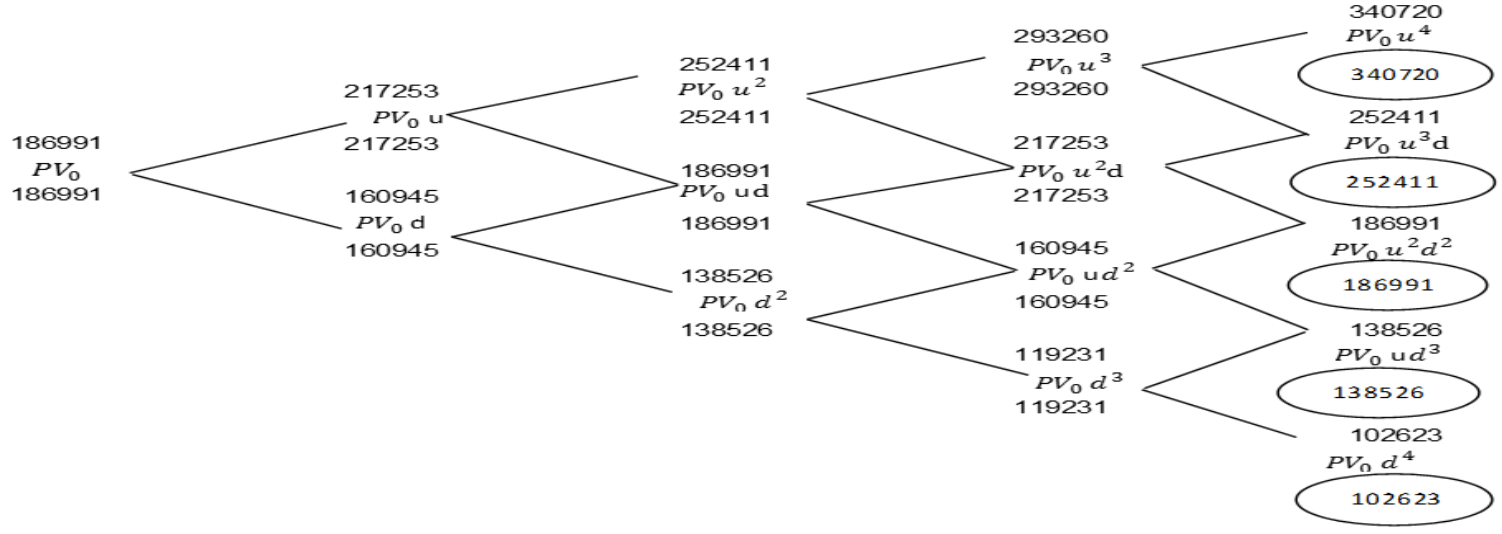

Fig. 6 LP Strategy 
Based on the above approaches, HP and CP strategies are resulted in higher option values so LP could not be an appropriate strategy; therefore these two policies will be scrutinized and compared as follows:

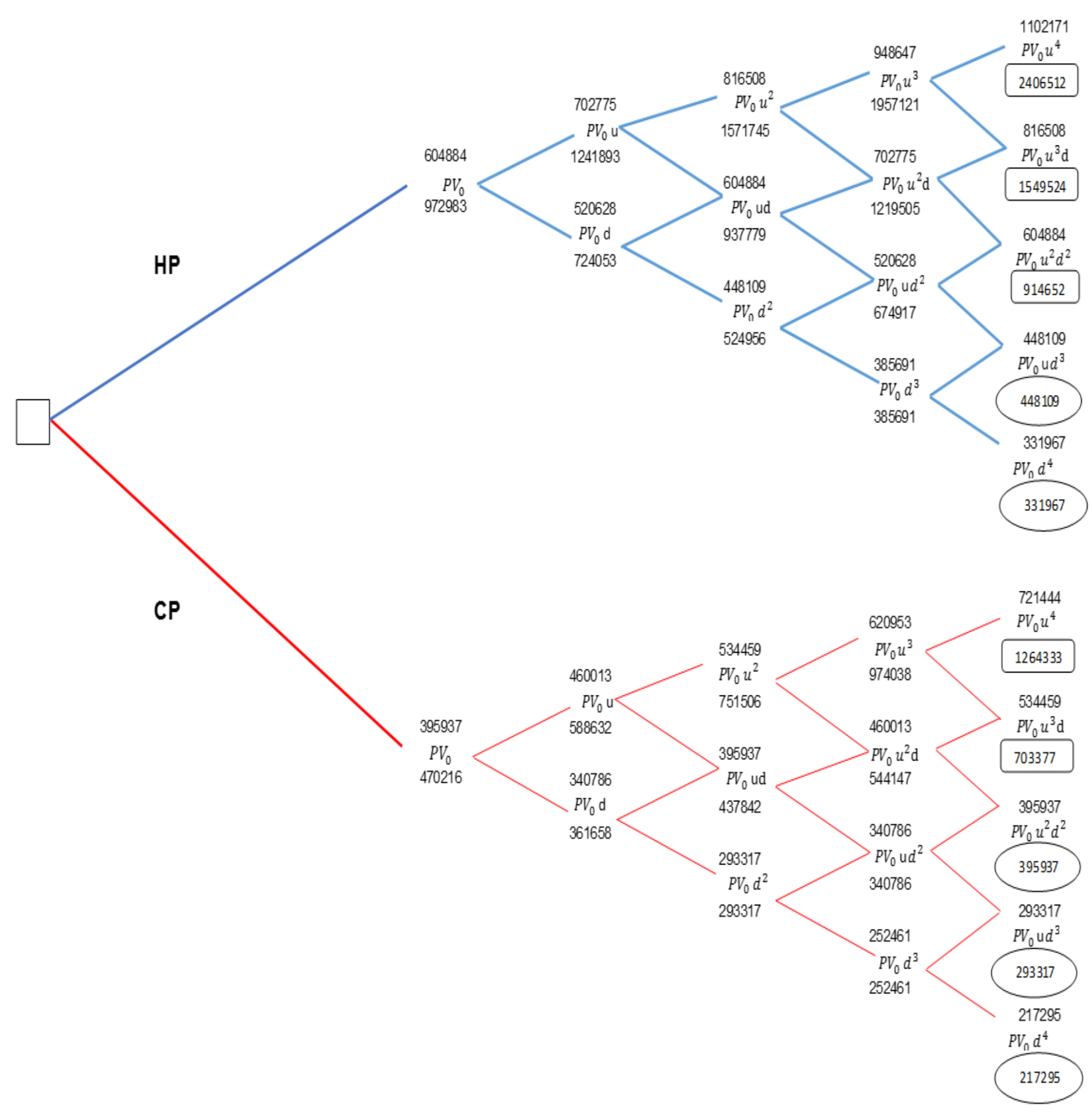

Fig. 7 HP and CP Project Valuation

In figures 4, 5, 6, and 7, all numbers are in dollars, top numbers are project values, bottom numbers are option values, rectangle option values indicate project expansion, and circled option values indicate the end of the project. 
Figure 7 illustrates that the HP strategy has been resulted in a higher option value; therefore, in the next subsection the expected profits of these two strategies will be calculated and choosing the best strategy for selling the product, based on the different situations, will be discussed.

\section{4-2- Expected Profits For Chosen Pricing Strategies}

As it resulted above, high pricing or contingent pricing could be the appropriate selling strategies in this project; hence, these two policies under different conditions will be scrutinized.
Our benchmark case is analyzed by assuming two scenarios namely considering IOT investment or ignoring it. Besides, with the aid of market research, we consider $P_{H}=365, P_{L}=206, P_{S}=154, \mathrm{c}=1.25$, and $v_{L 0}=300$ to calculate expected profits of these strategies. Figures $8-12$ imply these scenarios as follows:

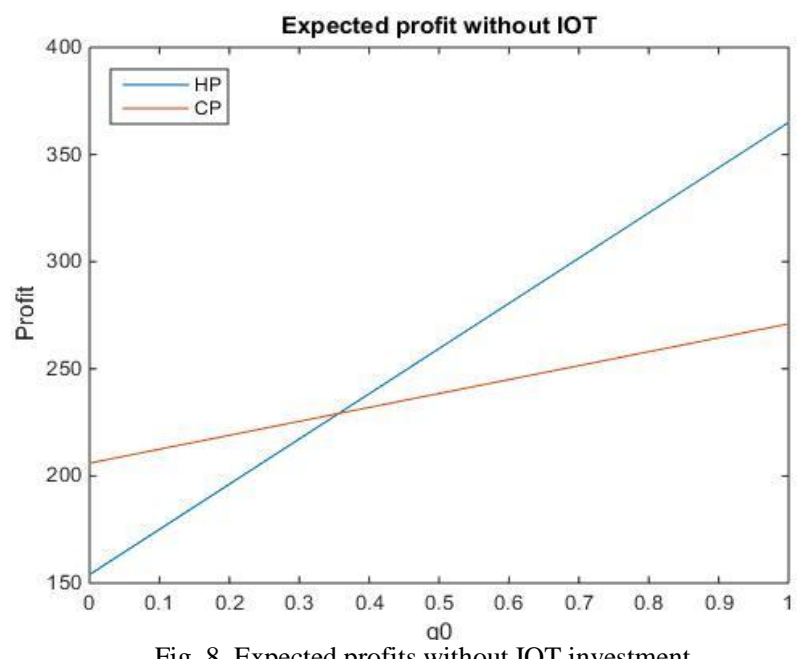

Fig. 8 Expected profits without IOT investment

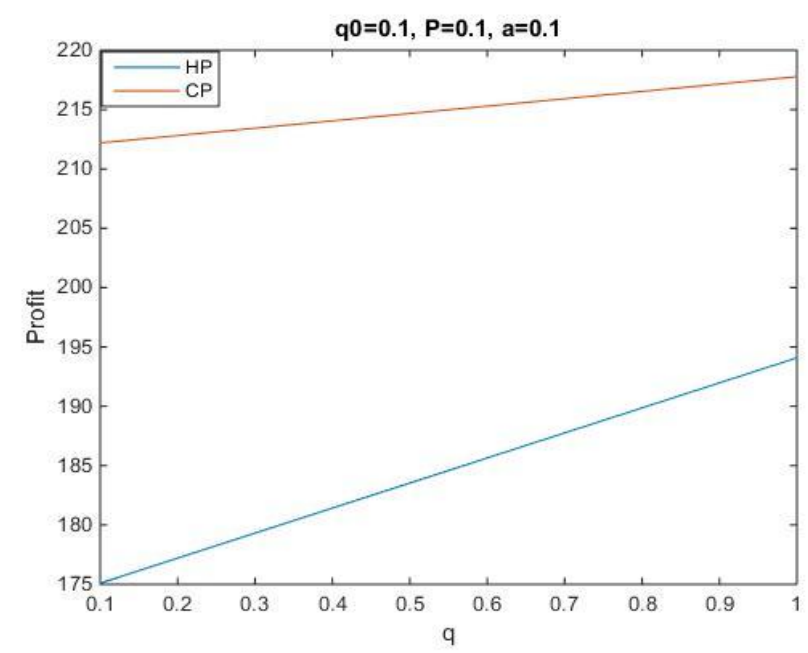

Fig. 9 Expected profits with IOT investment, $\mathrm{q}_{0}=0.1, \rho=0.1$, $\mathrm{a}=0.1$

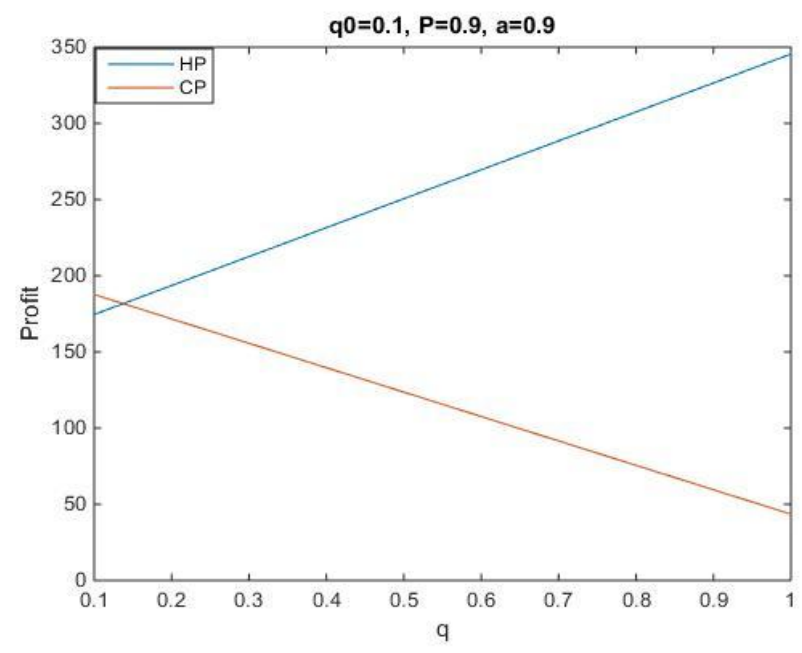

Fig. 10 Expected profits with IOT investment, $q_{0}=0.1, \rho=0.9$, $\mathrm{a}=0.9$ 


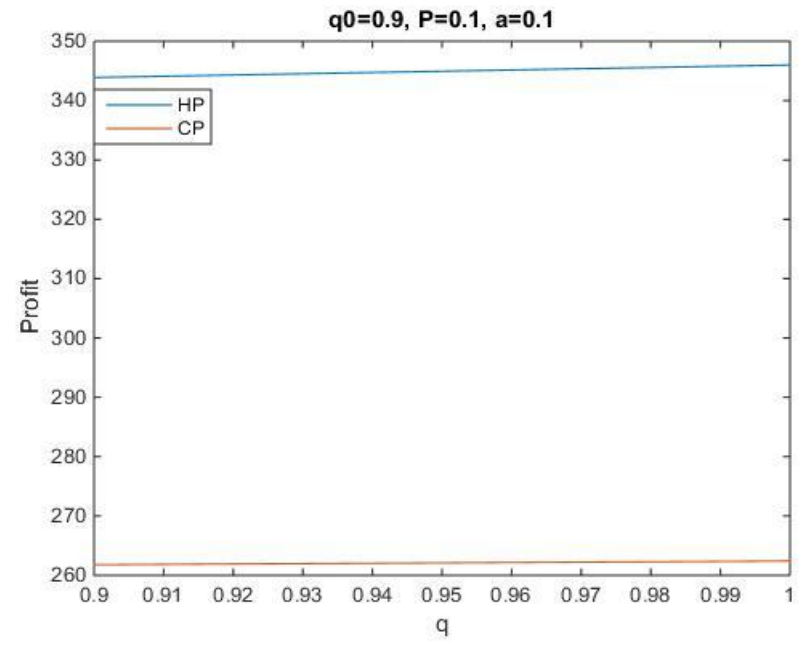

Fig. 11 Expected profits with IOT investment, $\mathrm{q}_{0}=0.9 \rho=0.1$, $\mathrm{a}=0.1$

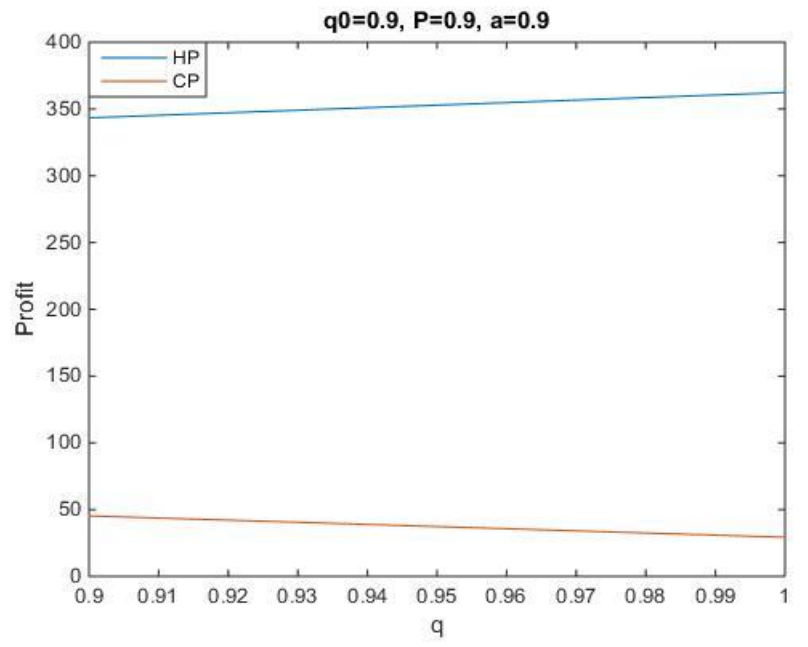

Fig. 12 Expected profits with IOT investment, $\mathrm{q}_{0}=0.9, \rho=0.9$, $\mathrm{a}=0.9$

Table 2: choosing the appropriate pricing strategies with considering IOT investment

\begin{tabular}{|c|c|c|c|}
\hline $\boldsymbol{q}_{\mathbf{0}}$ & $\boldsymbol{\rho}$ & $\mathbf{a}$ & Chosen pricing strategy \\
\hline 0.1 & 0.1 & 0.1 & CP \\
\hline 0.1 & 0.9 & 0.9 & If $\mathrm{q}>0.14$, HP will be chosen. \\
\hline 0.9 & 0.1 & 0.1 & HP \\
\hline 0.9 & 0.9 & 0.9 & HP \\
\hline
\end{tabular}

Figure 8 illustrates that without investing in IOT, if $\mathrm{q} 0<0.36, \mathrm{CP}$ will be chosen as the pricing strategy for the firm, otherwise, HP. On the other hand, when the IOT investment is applied, different cases could be analyzed. When the initial purchasing likelihood of the HV consumer is low and the firm does not invest in a high level on IOT, CP will be our selected policy because of the uncertainty that the firm has confronted. However, if the firm invests highly in IOT and the product value has been affected by this investment, for $\mathrm{q}>0.14 \mathrm{Hp}$ will be the appropriate strategy. It means that if the HV consumer purchasing likelihood is 0.15 , we can apply HP strategy, while in the case without IOT investment or low-level investment, CP strategy will be implemented.

In the other words, investing in IOT will lead to produce products which the consumers are willing to buy, target more HV consumers, decrease the firm's uncertainty and following that, implementing HP strategy to obtain higher profits. It is also shown that if the IOT investment level affects product value in the consumer's opinion, HP will be more appealing than CP. Comparing figures 9 and 10 reveals that, investing highly in IOT has targeted more HV consumers and resulted in a higher expected profit.

Moreover, when the initial purchasing likelihood of the HV consumer is high, investing in IOT is not necessary due to the privilege of the HP strategy for any amounts of q. However, even in this situation, the more investing in IOT, the higher profits will be obtained as it is shown in figures 11 and 12.

Based on what has been analyzed, we can conclude that the scenarios which were resulted in a higher option value, could be chosen as the IOT-based firms' pricing policies. In this study, among the mentioned scenarios which are related to pricing strategies, HP was selected as the best one. The results can also verify that HP strategy can be resulted in higher profits with the aid of the IOT investment. 


\section{5- Conclusions}

Technology-based projects especially IT and IOT projects are not common because of high initial investments and demand uncertainties that they may face during the project execution. Applying real options in our investment can lead to mitigating the mentioned demand uncertainties and the risk of high initial investments. Various types of real options can be implemented during the project; since our case was an IOT-device expansion project, we comprehensively focused on option to expand in this study.

Because IOT is introduced as an emerging technology in recent years, selling strategies of these products must be chosen appropriately to obtain the highest profit for the firm. Investing in IOT as it leads to improving consumer targeting can decrease the demand uncertainty in this condition. Choosing appropriate static and dynamic selling strategies namely low-pricing, high-pricing, and contingent pricing strategies that are integrated with IOT investment can be a useful solution for this problem. Comparing these strategies resulted that HP and CP under special situations depend on the firm certainty can be our policy; however, LP strategy will never be chosen. In other words, if the IOT investment level and the purchasing likelihood of an $\mathrm{HV}$ consumer is high, the HP strategy will be selected because of obtaining a higher expected profit. On the other hand, if the firm is uncertain about HV consumer's arrival, contingent pricing combined with IOT investment will lead to obtaining higher profit for the firm.

Although this paper provides new insights, the model may not be implemented for service cases as it just focuses on product projects, so One direction for future research is to scrutinize IOT-based service firms. Moreover, including other pricing strategies such as probabilistic selling in trinomial decision lattices can be suggested for future research.

\section{References}

[1] X. Zhang and W. T. Yue, "Transformative value of the Internet of Things and pricing decisions," Electronic Commerce Research and Applications, vol. 34, No. November 2018, 2019, p. 100825.

[2] L. Atzori, A. Iera, and G. Morabito, "The Internet of Things: A survey," Computer Networks, vol. 54, No. 15, 2010, pp. 2787-2805.

[3] S. Kim and S. Kim, "A multi-criteria approach toward discovering killer IoT application in Korea," Technological Forecasting and Social Change, vol. 102, 2016, pp. 143-155.
[4] S. Cuomo, P. De Michele, F. Piccialli, A. Galletti, and J. E. Jung, "IoT-based collaborative reputation system for associating visitors and artworks in a cultural scenario," Expert Systems with Applications, vol. 79, 2017, pp. 101-111.

[5] Y. H. Tehrani, Z. Fazel, and S. M. Atarodi, "A survey of two dominant low power and long range communication technologies," Journal of Information Systems and Telecommunication, vol. 6, No. 2, 2018, pp. 60-66.

[6] M. Fasanghari and A. Keramati, "Customer Churn Prediction Using Local Linear Model Tree for Iranian Telecommunication Companies," Journal of Industrial Engineering, University of Tehran, 2011, pp. 25-37.

[7] M. Fasanghari, "E-Commerce Assessment in Fuzzy Situation,"in E-commerce, Shangha, China: InTech, 2010, ch. 2, pp. 21-31.

[8] J. C. Cox, S. A. Ross, and M. Rubinstein, "Option pricing: A simplified approach," Journal of Financial Economics, vol. 7, No. 3, 1979, pp. 229-263.

[9] P. Tufano and T. Copeland, "A Real-World Way to Manage Real Options," Harvard Business Review, Vol. 82, 2004, pp. 90-99.

[10] T. Copeland and V. Antikarov, Real options, New York: Texere LLC, 2001.

[11] L. E. Brandão, J. S. Dyer, and W. J. Hahn, "Using Binomial Decision Trees to Solve Real-Option Valuation Problems," Decision Analysis, vol. 2, No. 2, 2005, pp. 69 88.

[12] D. Singh, G. Tripathi, and A. J. Jara, "A survey of Internetof-Things: Future vision, architecture, challenges and services," in 2014 IEEE World Forum on Internet of Things (WF-IoT), Mar. 2014, pp. 287-292.

[13] A. Čolaković and M. Hadžialić, "Internet of Things (IoT): A review of enabling technologies, challenges, and open research issues," Computer Networks, vol. 144, 2018, pp. 17-39.

[14] M. H. Miraz, M. Ali, P. S. Excell, and R. Picking, "A review on Internet of Things (IoT), Internet of Everything (IoE) and Internet of Nano Things (IoNT)," in 2015 Internet Technologies and Applications, ITA 2015 - Proceedings of the 6th International Conference, 2015, pp. 219-224.

[15] H. Lamaazi, N. Benamar, A. J. Jara, L. Ladid, and D. El Ouadghiri, "Challenges of the Internet of Things: IPv6 and Network Management," in 2014 Eighth International Conference on Innovative Mobile and Internet Services in Ubiquitous Computing, Jul. 2014, pp. 328-333.

[16] H. Hamidi, "Safe use of the internet of things for privacy enhancing," Journal of Information Systems and Telecommunication, vol. 4, No. 3, 2016, pp. 145-151.

[17] S. Fay and J. Xie, "Probabilistic goods: A creative way of selling products and services," Marketing Science, vol. 27, No. 4, 2008, pp. 674-690.

[18] G. Gallego, S. G. Kou, and R. Phillips, "Revenue management of callable products," Management Science, vol. 54, No. 3, 2008, pp. 550-564.

[19] V. Mak, A. Rapoport, and E. J. Gisches, "Competitive dynamic pricing with alternating offers: Theory and experiment," Games and Economic Behavior, vol. 75, No. 1, 2012, pp. 250-264. 
[20] I. P. L. Png and H. Wang, "Buyer uncertainty and two-part pricing: Theory and applications," Management Science, vol. 56, No. 2, 2010, pp. 334-342.

[21] M. Kremer, B. Mantin, and A. Ovchinnikov, " Dynamic Pricing in the Presence of Myopic and Strategic Consumers: Theory and Experiment," Production and Operations Management, vol. 26, No. 1. 2017, pp. 116-133.

[22] L. Cabral, "Dynamic pricing in customer markets with switching costs," Review of Economic Dynamics, vol. 20, 2016, pp. 43-62.

[23] J. J. Anton, G. Biglaiser, and N. Vettas, "Dynamic price competition with capacity constraints and a strategic buyer," International Economic Review, vol. 55, No. 3, 2014, pp. 943-958.

[24] E. Biyalogorsky and E. Gerstner, "Contingent Pricing to Reduce Price Risks," Marketing Science, vol. 23, No. 1, 2004, pp. 146-155.

[25] H. A. Najafabadi, A. Shekarchizadeh, A. Nabiollahi, N. Khani, and H. Rastegari, "The innovation roadmap and value creation for information goods pricing as an economic commodity," Journal of Information Systems and Telecommunication, vol. 7, No. 2, 2019, pp. 154-164.

[26] H. K. Bhargava and S. Sundaresan, "Contingency Pricing for Information Goods and Services under Industrywide Performance Standard," Journal of Management Information Systems, vol. 20, No. 2, 2003, pp. 113-136.

[27] F. Black and M. Scholes, "The pricing of options and corporate liabilities," Journal of Political Economy, vol. 81, No. 3, 1973, pp. 637-657.

[28] P. Kodukula and Ch. Papudesu , Project Valuation Using Real Options Analysis, A practitioner's Guide, J. Ross Publishing, 2006.

[29] X. Li and J. D. Johnson, "Opportunities Using Real Options Theory," Information Resources Management Journal, vol. 15, No. 3, 2002, pp. 32-47.

[30] J. Zhang, S. Bandyopadhyay, and S. Piramuthu,

"Real option valuation on grid computing," Decision Support Systems, vol. 46, No. 1, 2008, pp. 333-343.

Nazanin Talebolfakhr is a master's student of Financial MBA at K. N. Toosi University of Technology. She received her BSc degree in industrial engineering from Kharazmi University in 2018 and as a top student was accepted at the master level. Her research interests include pricing, Ebusiness, internet of things, innovative project valuation, and decision modelling.

Seyed Babak Ebrahimi is a Top Iranian young Researcher in Science and Technology 2014 and Elected as the Best Ph.D. Student's in 2014. He earned his MSc from Sharif University of Technology as a top student in the field of economics. During his undergraduate period, he was awarded as the best student in research at the Department of Industrial Engineering of Iran University of Science and Technology for three consecutive years. His research interests include econometrics, pricing, E-Commerce, time series analysis and pricing.
Donya Rahmani received her BSc degree from Bu-Ali Sina University, Hamedan, Iran, and MS and Ph.D. degrees from Iran University of Science and Technology, Tehran, Iran, all in Industrial Engineering. She is currently an Associate Professor of Industrial Engineering at K. N. Toosi University of Technology, and she is the reviewer of several international journals. Her research interests include sustainability, supply chain design, robust optimization, Energy systems modelling, Disaster management, and design of decision support systems. 